\title{
Comparative Performance of Tetraphosphonate and Diphosphonate as Reverse Osmosis Scale Inhibitors
}

\author{
Alexey Andrianov ${ }^{1,{ }^{*},}$,Maria Danilycheva ${ }^{1}$, Stefania Liakaki-Stavropoulou $^{2}$ and \\ Konstantinos D. Demadis ${ }^{2}$, Roman Efremov ${ }^{1}$ \\ ${ }^{1}$ Moscow State University of Civil Engineering, Yaroslavskoe shosse 26, Moscow, 129337, Russia \\ ${ }^{2}$ Crystal Engineering, Growth \& Design Laboratory, Department of Chemistry, University of Crete, \\ Voutes Campus, Heraklion, Crete, GR-71003, Greece
}

\begin{abstract}
Reverse osmosis (RO) technologies are widely used throughout the world for drinking, industrial and waste water treatment purposes. Proper and economically attractive operation of RO installations should be provided by the correct maintenance of all technical process parameters. One of the significant operational problems is precipitation and deposition of sparingly-soluble salts on the membrane surface, which can be prevented by dosing special chemical additives into the feed solution. The aim of the present work is to reveal the structure/function relationship of phosphonate scale inhibitors, which possess systematic structural similarities and differences. Specifically, two classes of tetraphosphonate ( 5 additives) and diphosphonate (6 additives) have been tested as calcium carbonate scale inhibitors on the lab membrane unit. It was found that among the family of tetraphosphonates and diphosphonates the inhibitor efficiency increases with elongation $-\left(\mathrm{CH}_{2}\right)-$ chain, but the longest additives have a sharp drop in inhibition efficiency.
\end{abstract}

\section{Introduction}

Reverse osmosis is the predominant desalination technique for various applications. In spite of its efficiency, there are certain fundamental issues that cause operational problems. One of these is precipitation of sparingly-soluble salts on membrane surface, which changes the operating mode, deteriorates the product water quality and shortens the operating time of the membrane modules. Antiscalant dosing is one of the most widespread methods to prevent scaling. A wide number of chemical additives cab be applied for maintaining sustainable operation of reverse osmosis installations. The most widely accepted mechanistic scenario is that these chemicals stop or interfere with inorganic scale nucleation, precipitation and adherence to equipment surfaces.

Several kinetics and mechanistic studies of scale inhibitor application have been investigated for prevention of undesirable effects $[1,2]$. Environmentally-friendly polymers

\footnotetext{
* Corresponding author: alexei-waterlab@yandex.ru
} 
have been developed to reduce hazardous post effect of discharging RO concentrate into surface water. However, based on these investigations, the most popular application approaches of scale inhibitors are still based on (poly)phosphonates [3-6]. They are readily soluble in water, non-toxic and effective at low treatment concentrations [7]. Moreover these inhibitors have high stability even at relatively high temperature [8] and severe operating conditions.

In addition to traditional phosphonates, more complex compounds, for example, diphosphonate or tetraphosphonates, are synthesized and studied [3, 9]. Previous studies of di- and tetra-phosphonates conducted by the authors did not include the determination of their effectiveness in conditions of reverse osmosis desalination, especially for calcium carbonate scale prevention.

\section{Materials and methods}

The antiscalant behavior of the synthesized phosphonate compounds was evaluated in several series of experiments for the inhibition of calcium carbonate scale formation. A model supersaturated solution was prepared by careful mixing of solutions of $\mathrm{MgSO}_{4}$, $\mathrm{NaHCO}_{3}$ and $\mathrm{CaCl}_{2}$ in distilled water. Final composition of feed solution had total hardness $7 \mathrm{mg} / \mathrm{L}$, calcium $6 \mathrm{mg} / \mathrm{L}, \mathrm{pH}=9$ and TDS was about $850 \mathrm{mg} / \mathrm{L}$. $\mathrm{pH}$ of feed solution was adjusted by addition of $\mathrm{HCl}$ aqueous solution.

Two classes of phosphonate inhibitors, namely, diphosphonates (6 additives) (Table 1) and tetraphosphonates (5 additives) (Table 2), were supplied by the Crystal Engineering, Growth \& Design Laboratory, University of Crete (Greece). These two families of additives possess the same functionality, amino-bis(methylenephosphonic acid). Tetraphosphonates possess two of these (one on each end) and diphosphonates have one (only on one end). The members of both families demonstrate a systematic elongation of the organic polymethylene portion, i.e. tetraphosphonates possess a $-\left(\mathrm{CH}_{2}\right)_{x}-(\mathrm{x}=2,4,6,8$, 12) chain bridging the two $\mathrm{N}$ atoms, whereas diphosphonates possess $\mathrm{a}-\left(\mathrm{CH}_{2}\right)_{\mathrm{x}} \mathrm{CH}_{3}(\mathrm{x}=0$, $1,3,5,7,11)$ non-polar side-chain [9].

Table 1. Diphosphonate scale inhibitors.

\begin{tabular}{|c|c|c|c|}
\hline $\begin{array}{c}\text { Additive } \\
\text { abbreviation }\end{array}$ & Additive Name & Additive Schematic Structure & $\begin{array}{c}\text { Molecular } \\
\text { weight }\end{array}$ \\
\hline $\begin{array}{l}\text { MBMP } \\
\left(\mathrm{C}_{1}-\mathrm{D}\right)\end{array}$ & $\begin{array}{l}\text { Methylamine-bis } \\
\text { (methylenephosphonic } \\
\text { acid) }\end{array}$ & & $\begin{array}{l}212 \mathrm{~g} / \mathrm{mol}, \\
\text { as acid }\end{array}$ \\
\hline $\begin{array}{l}\text { EBMP } \\
\left(\mathrm{C}_{2}-\mathrm{D}\right)\end{array}$ & $\begin{array}{l}\text { Ethyleneamine-bis } \\
\text { (methylenephosphonic } \\
\text { acid) }\end{array}$ & & $\begin{array}{l}226 \mathrm{~g} / \mathrm{mol} \text {, } \\
\text { as acid }\end{array}$ \\
\hline $\begin{array}{l}\text { BBMP } \\
\left(\mathrm{C}_{4}-\mathrm{D}\right)\end{array}$ & $\begin{array}{l}\text { Butyleneamine-bis } \\
\text { (methylenephosphonic } \\
\text { acid) }\end{array}$ & & $\begin{array}{l}254 \mathrm{~g} / \mathrm{mol} \text {, } \\
\text { as acid }\end{array}$ \\
\hline
\end{tabular}


Table 1 (continuation)

\begin{tabular}{|l|l|l|l|}
\hline $\begin{array}{l}\text { HBMP-D } \\
\text { (C6-D) }\end{array}$ & $\begin{array}{l}\text { Hexamethyleneamine -bis } \\
\text { (methylenephosphonic } \\
\text { acid) }\end{array}$ \\
\hline $\begin{array}{l}\text { OBMP-D } \\
\text { (C8-D) }\end{array}$ & $\begin{array}{l}\text { Octamethyleneamine-bis } \\
\text { (methylenephosphonic } \\
\text { acid) }\end{array}$ & $\begin{array}{l}\text { Dodecamethyleneami ne- } \\
\text { acid) }\end{array}$ &
\end{tabular}

Table 2. Tetraphosphonate scale inhibitors.

\begin{tabular}{|c|c|c|c|}
\hline $\begin{array}{c}\text { Additive } \\
\text { abbreviation }\end{array}$ & Additive Name & Additive Schematic Structure & $\begin{array}{c}\text { Molecular } \\
\text { weight }\end{array}$ \\
\hline $\begin{array}{l}\text { EDTMP } \\
\text { (C2) }\end{array}$ & $\begin{array}{l}\text { Ethylenediaminetetrakis } \\
\text { (methylenephosphonic } \\
\text { acid) }\end{array}$ & & $\begin{array}{l}436 \mathrm{~g} / \mathrm{mol}, \\
\text { as acid } \\
546 \mathrm{~g} / \mathrm{mol} \text {, } \\
\text { as penta- } \\
\text { sodium salt }\end{array}$ \\
\hline $\begin{array}{l}\text { TMTMP } \\
\text { (C4) }\end{array}$ & $\begin{array}{l}\text { tetramethylenediamine- } \\
\text { tetrakis } \\
\text { (methylenephosphonic } \\
\text { acid) }\end{array}$ & & $\begin{array}{l}464 \mathrm{~g} / \mathrm{mol} \text {, } \\
\text { as acid }\end{array}$ \\
\hline $\begin{array}{l}\text { HDTMP } \\
\text { (C6) }\end{array}$ & $\begin{array}{l}\text { hexamethylenediamine- } \\
\text { tetrakis } \\
\text { (methylenephosphonic } \\
\text { acid) }\end{array}$ & & $\begin{array}{l}492 \mathrm{~g} / \mathrm{mol} \text {, } \\
\text { as acid }\end{array}$ \\
\hline $\begin{array}{l}\text { ODTMP } \\
\text { (C8) }\end{array}$ & $\begin{array}{l}\text { Octamethylenediamine- } \\
\text { tetrakis } \\
\text { (methylenephosphonic } \\
\text { acid) }\end{array}$ & & $\begin{array}{l}520 \mathrm{~g} / \mathrm{mol} \text {, } \\
\text { as acid }\end{array}$ \\
\hline $\begin{array}{l}\text { DDTMP } \\
(\mathrm{C} 12)\end{array}$ & $\begin{array}{l}\text { Dodecamethylenedia- } \\
\text { mine-tetrakis } \\
\text { (methylenephosphonic } \\
\text { acid) }\end{array}$ & & $\begin{array}{l}586 \mathrm{~g} / \mathrm{mol}, \\
\text { as acid }\end{array}$ \\
\hline
\end{tabular}


Scaling tests were carried out using a small lab membrane unit equipped with the spiral wound module TW 30-1812-50 (DOW Filmtec, USA) with reverse osmosis polyamide membranes with selectivity up to $98 \%$. The transmembrane pressure was maintained at 6 bar (the maximum pressure provided by the existing RO pump). All scaling tests were conducted in circulation mode whereby reject flow (concentrate) was returned to the feed water tank and permeate was collected in a separate tank. To initiate calcium carbonate scaling, high supersaturation was constantly maintained due to operation of the test unit in concentration mode where product water was withdrawn. This series of scaling experiments was conducted by various new phosphonate scale inhibitors at the most efficient concentration of $5 \mathrm{ppm}$ in order to correlate results with previous investigations [10].

The samples were taken from initial feed solution and circulated solution (for various concentration ratios) - from tank (1, Fig. 1), and for permeate - from tank (4, Fig. 1) (one sample characterized the average quality of product water).

In all samples the following parameters are determined: temperature, TDS (conductivity), $\mathrm{pH}$, total hardness, total alkalinity, and calcium. Conductivity and temperature are controlled by a laboratory conductivity meter Cond 730 (WTW inoLab ${ }^{\circledR}$ ); pH value - using laboratory pH meter HI 2215 (Hanna Instruments); total alkalinity - by titration with $\mathrm{HCl}$; and total hardness and calcium - by complexometric EDTA titration.

To restore the membrane element's productivity and to remove accumulated precipitation, chemical washing was conducted between series of experiments using a $2 \%$ solution of citric acid.

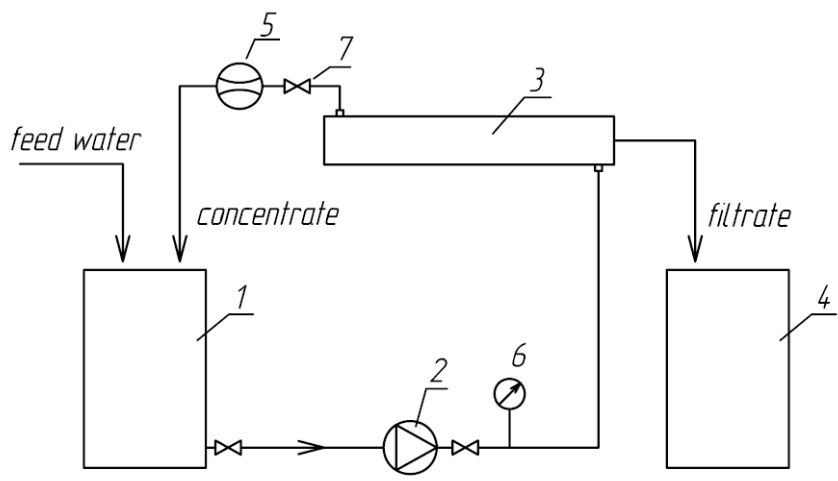

Fig. 1. Schematic diagram of laboratory membrane RO unit for membrane scaling tests: 1 - feed water tank; 2 - pump; 3 - spiral wound membrane module; 4 - permeate tank; 5 - concentrate rotameter; 6 - pressure-gauge

The amount of $\mathrm{CaCO}_{3}$ scales accumulated in the membrane module was calculated as a difference between initial amount of calcium in the feed solution and total amount of calcium in concentrate (circulating solution) and permeate. Antiscalant performance was evaluated by comparison of scaling rate values determined throughout experiments with, and without antiscalant dosing. Antiscalant efficiency as a calcium carbonate and calcium sulphate inhibitor was calculated by using the following equation:

$$
E(\%)=\frac{M_{C a}^{\text {blank }}-M_{C a}^{\text {antiscalant }}}{M_{C a}^{\text {blank }}} \cdot 100
$$

where $M_{C a}^{\text {blank }}$ and $M_{C a}^{\text {antiscalant }}$ are the mass of calcium accumulated in membrane module in the absence of antiscalant and with antiscalant dosing respectively, mg. 
Scaling test for each reagent was repeated 2-3 times and the average antiscalant efficiency was calculated.

\section{Results and discussion}

The results show that changes in the chemical structure of an inhibitor molecule have an effect on inhibitory efficiency. Most additives improved the process and prevented scale formation in the membrane module.

Tetraphosphonates revealed a systematic antiscaling efficiency that dependents on the length of the bridging units $-\left(\mathrm{CH}_{2}\right)_{x}-(\mathrm{x}=2,4,6,8,12)$ (Fig. 2, Table 3). Specifically, the scale inhibition efficiency ranking was $2<4<6<8$. These results reveal the tendency of decreasing of inhibition effect is proportional to the number of methylene groups on the side-chain. However the inhibitor DDTMP (C12) with $\mathrm{x}=12$ showed reduced efficiency (between EDTMP and TMTMP). In general, the experimental results with tetraphosphonates show a similar tendency obtained in [9] for calcium sulphate crystallization (with the exception of DDTMP performance).

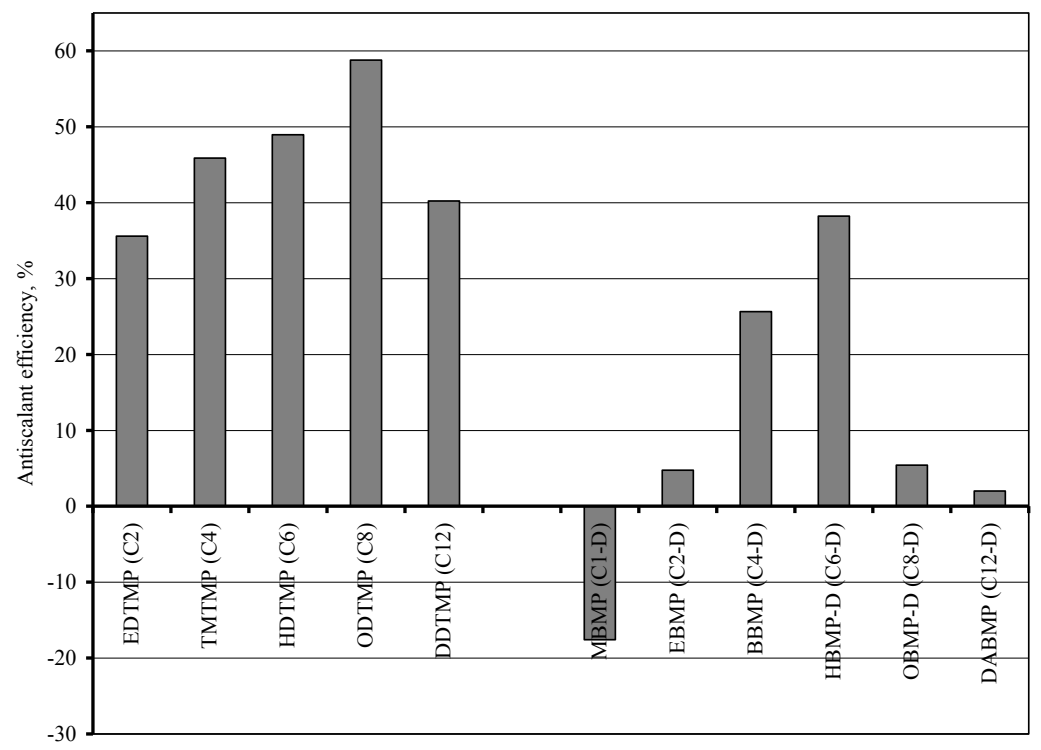

Fig. 2. Tetraphosphonate and diphosphonate scale inhibitors performance.

The similar trend was observed for diphosphonates, i.e. the longer the side-chain length, the higher the efficiency, but extremely long chain causes the deterioration of antiscalant efficiency (Fig. 2, Table 3). Additives with the longest and most hydrophobic side chains, i.e. OBMP (C8-D) and DABMP (C12-D), in the beginning restrained calcium carbonate nucleation, but subsequent growth is dramatically increased (Fig. 3). Lower antiscalant efficiency was coupled with lower RO membrane flux. Decrease in efficiency, that is an increase in the amount of calcium carbonate scale on the membrane, can be explained by a longer duration of the experiment (from 2 to 4.5 hours against 0.8-1.3 hours for other additives), which is caused by a lower flow through the membrane during these tests. Perhaps the effectiveness of OBMP and DABMP as inhibitors are high, but the reagents themselves were deposited on the membrane and reduced its productivity. This phenomenon requires verification - further scaling experiments with the SEM examination of the membrane surface. It is interesting that the first diphosphonate MBMP (C1-D) 
demonstrated negative efficiency - on the contrary, it increased the formation of calcium carbonate sediment on the membrane surface. At the same time, this did not cause a noticeable increase in the duration of the scaling tests as for OBMP and DABMP additives.

Table 3. Antiscalant efficiency in reverse osmosis tests.

\begin{tabular}{|c|c|c|c|}
\hline Antiscalant & $\begin{array}{c}\text { Dosage, } \\
\mathrm{mg} / \mathrm{L}\end{array}$ & $\begin{array}{c}\text { Avarage tets } \\
\text { duration, hours }\end{array}$ & $\begin{array}{c}\text { Inhibitor } \\
\text { efficiency, \% }\end{array}$ \\
\hline EDTMP (C2) & 5,0 & 1.25 & 36 \\
\hline TMTMP (C4) & 5,0 & 1.33 & 46 \\
\hline HDTMP (C6) & 5,0 & 0.93 & 49 \\
\hline ODTMP (C8) & 5,0 & 0.93 & 59 \\
\hline DDTMP (C12) & 5,0 & 1.34 & 40 \\
\hline \hline MBMP (C1-D) & 5,0 & 1.10 & -18 \\
\hline EBMP (C2-D) & 5,0 & 1.07 & 5 \\
\hline BBMP (C4-D) & 5,0 & 0.75 & 26 \\
\hline HBMP-D (C6-D) & 5,0 & 0.84 & 38 \\
\hline OBMP-D (C8-D) & 5,0 & 1.90 & 5 \\
\hline DABMP (C12-D) & 5,0 & 4.50 & 2 \\
\hline \multicolumn{2}{|r|}{} & &
\end{tabular}

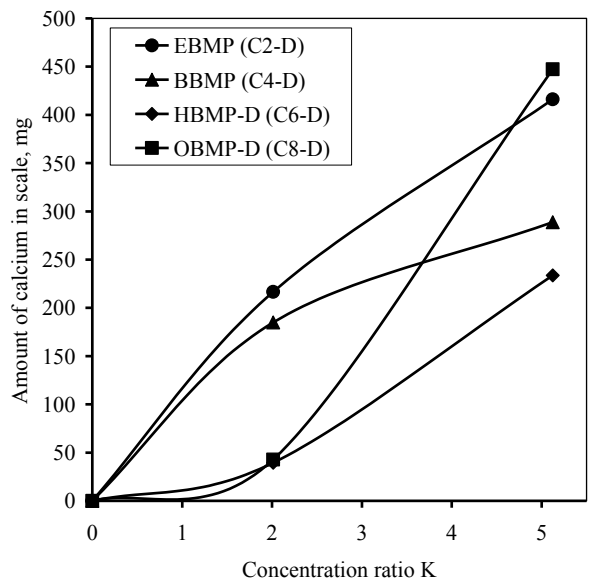

Fig. 3. Amount of calcium accumulated in membrane module versus concentration ratio.

Generally, diphosphonates showed a much lower inhibitory efficiency in comparison with tetraphosphonates. It has been reported that the number of adsorption active centers in the molecule directly promotes inhibition process $[11,12]$. Tetraphosphonates can interact by one amino-bis(methylenephosphonate) moiety with a calcium ion on the crystal surface or by two aminobis(methylenephosphonate) groups with neighboring surface calcium ions [9]. However, it is important to note that in the diphosphonate family of inhibitors, the number of active centers i.e. the phosphonate centers on the molecule backbone is the same for all diphosphonates. The polymethylene non-polar side-chain certainly does not contribute to the inhibition process, because it cannot interact with the mineral surface. Hence the systematic elongation of the side-chain undoubtedly is related to the mobility of the inhibitor molecule. Apparently, as the molecule becomes larger (due to elongation), its access to the surface of the forming nuclei becomes profoundly restricted. This is confirmed by the fact that the "longest" diphosphonates OBMP (C8-D) and DABMP (C12D) and tetraphosphonate DDTMP (C12) are the least efficient. 
Nalbach [13] reported a structural influence of the inhibitor molecule (either diphosphonates or tetraphosphonates) on the dissolution of calcite. That conjecture can be supported by our current tests.

\section{Conclusions}

Evaluation of the efficiency of several organophosphate scale inhibitors in a RO unit revealed that the most diphosphanate and tetraphosphonate additives reduced calcium carbonate formation in membrane module. Phosphonate additives interact with the calcium carbonate crystal surface, thus preventing crystal growth. It was found that among the family of tetraphosphonates the most efficient ones were those with the longer polymetylene bridging chain, except the longest one - dodecamethylenediaminetetrakis(methylenephosphonic acid). The some behavior demonstrated by diphosphonate family: the inhibitor efficiency increases with elongation of $-\left(\mathrm{CH}_{2}\right)$ - chain, but starting with the octamethylenediamine-tetrakis (methylenephosphonic acid) there is a reverse trend. These results are helpful in evaluating the effective synergy of the system "salt solution - inhibitor - RO membrane" and obtain useful insights for further industrial application.

\section{References}

1. W.N. Al Nasser, F.H. Al Salhi, Powder Technology 270, 548-560 (2015)

2. A. Khormali, D.G. Petrakov, R.N. Moghaddam, J. of Petroleum Sci. and Eng. 153, 257-267 (2017)

3. K.E. Papathanasiou, K.D. Demadis. Phosphonates in Matrices. Tailored Organic Inorganic Materials, Ch. 3. (John Wiley \& Sons, Inc., 2015)

4. M.F.B. Sousa, F. Signorelli, C.A. Bertran, J. of Petroleum Sci. and Eng 147, 468-473 (2016)

5. J. Tang, D. Cao, Y. Wang, C. Mohamad, L. Chen, H. Wang, Int. J. Electrochem. Sci. 12, 11955-11971 (2017)

6. .Y. Ji, Y. Chen, J. Le, M. Qian, Y. Huan, W. Yang, X. Yin, Y. Liu, X. Wang, Y. Chen, Desalination 422, 165-173 (2017)

7. K.S. Sorbie, N. Laing, SPE International Symposium on Oilfield Scale, 26-27 May 2004, Aberdeen, United Kingdom, SPE-87470-MS (2004)

8. S.T. Liu, G.H. Nancollas, J. of Colloid and Interface Sci. 52, 593-601 (1975)

9. E. Akyol, M. Oner, E. Barouda, K.D. Demadis, Crystal growth and Design 9, 51455154 (2009)

10. A.G. Pervov, A.P. Andrianov, M.N. Danilycheva, Water Sci. and Tech.: Water Supply 18(2), ws2017106 (2017)

11. K.D. Demadis, E. Neofotistou, E. Mavredaki, M. Tsiknakis, E.-M. Sarigiannidou, S.D. Katarachia, Desalination 179, 281-295 (2005)

12. E. Mavredaki, A. Stathoulopoulou, E. Neofotistou, K.D. Demadis, Desalination 210, 257-265 (2007)

13. M. Nalbach, A. Moschona, K.D. Demadis, S. Klassen, R. Bechstein, A. Kühnle, Cryst. Growth Des. 17, 5867-5874 (2017) 